University of Wollongong

Research Online

Faculty of Engineering and Information

Faculty of Engineering and Information

Sciences - Papers: Part B

Sciences

2017

Osmotic membrane bioreactors for wastewater reuse: Performance comparison between cellulose triacetate and polyamide thin film composite membranes

\author{
Bangxi Zhang \\ China Agricultural University, Guizhou Institute of Agricultural Resources and Environment \\ Xiaoye Song \\ University of Wollongong, xs245@uowmail.edu.au \\ Long D. Nghiem \\ University of Wollongong, longn@uow.edu.au \\ Guoxue Li \\ China Agricultural University \\ Wenhai Luo \\ China Agricultural University, wl344@uowmail.edu.au
}

Follow this and additional works at: https://ro.uow.edu.au/eispapers1

Part of the Engineering Commons, and the Science and Technology Studies Commons

Research Online is the open access institutional repository for the University of Wollongong. For further information contact the UOW Library: research-pubs@uow.edu.au 


\title{
Osmotic membrane bioreactors for wastewater reuse: Performance comparison between cellulose triacetate and polyamide thin film composite membranes
}

\author{
Abstract \\ This study compared the performance of the asymmetric cellulose triacetate (CTA) and polyamide thin \\ film composite (TFC) forward osmosis (FO) membranes in an osmotic membrane bioreactor (OMBR). A \\ reverse osmosis (RO) system was integrated with OMBR to regenerate the draw solution and produce \\ clean water. Results show that the TFC membrane exhibited a higher initial water flux but more dramatic \\ flux decline compared to the CTA membrane when they were used for OMBR. The CTA and TFC \\ membranes also resulted in discernible difference in salinity build-up in the bioreactor and thus biomass \\ characteristics during OMBR operation. All 30 trace organic contaminants (TrOCs) selected in this study \\ were effectively removed by the OMBR-RO hybrid system regardless of the FO membrane type. Compared \\ to the CTA membrane, the TFC membrane contributed more significantly toward the removal of \\ hydrophilic and biologically persistent compounds and thus reduced their accumulation in the draw \\ solution during OMBR-RO operation. In addition, CTA and TFC FO membranes also resulted in \\ considerable differences in TrOC residuals in the sludge during OMBR operation.

\section{Disciplines} \\ Engineering | Science and Technology Studies

\section{Publication Details} \\ Zhang, B., Song, X., Nghiem, L. D., Li, G. \& Luo, W. (2017). Osmotic membrane bioreactors for wastewater \\ reuse: Performance comparison between cellulose triacetate and polyamide thin film composite \\ membranes. Journal of Membrane Science, 539 383-391.
}


1 Osmotic membrane bioreactors for wastewater reuse: Performance comparison between cellulose triacetate and polyamide thin film composite membranes

4

9 Bangxi Zhang ${ }^{\mathrm{a}, \mathrm{b}}$, Xiaoye Song ${ }^{\mathrm{c}}$, Long D. Nghiem ${ }^{\mathrm{c}}$, Guoxue Li ${ }^{\mathrm{a}}$, Wenhai Luo ${ }^{\mathrm{a}^{*}}$

$10{ }^{\mathrm{a}}$ Beijing Key Laboratory of Farmland Soil Pollution Prevention and Remediation, 11 College of Resources and Environmental Sciences, China Agricultural University, 12 Beijing, 100193, China

$13{ }^{\mathrm{b}}$ Guizhou Institute of Agricultural Resources and Environment, Guiyang, Guizhou, 14

${ }^{\mathrm{c}}$ Strategic Water Infrastructure Laboratory, School of Civil, Mining and

16 Environmental Engineering, University of Wollongong, Wollongong, NSW 2522, 17

Australia

* Corresponding author: luowenhai@ cau.edu.cn; Ph: +86 18311430503. 


\section{Abstract}

19 This study compared the performance between the asymmetric cellulose triacetate 20 (CTA) and polyamide thin film composite (TFC) forward osmosis (FO) membranes in 21 an osmotic membrane bioreactor (OMBR). A reverse osmosis (RO) system was 22 integrated with OMBR to regenerate the draw solution and produce clean water. 23 Results show that the TFC membrane exhibited a higher initial water flux but more 24 dramatic flux decline compared to the CTA membrane when they were used for 25 OMBR. The CTA and TFC membranes also resulted in discernible difference in 26 salinity build-up in the bioreactor and thus biomass characteristics during OMBR 27 operation. All 30 trace organic contaminants (TrOCs) selected in this study were 28 effectively removed by the OMBR-RO hybrid system regardless of the FO membrane 29 type. Compared to the CTA membrane, the TFC membrane contributed more 30 significantly toward the removal of hydrophilic and biologically persistent compounds 31 and thus reduced their accumulation in the draw solution during OMBR-RO operation. 32 In addition, CTA and TFC FO membranes also resulted in considerable differences in 33 TrOC residuals in the sludge during OMBR operation.

36 Keywords: Osmotic membrane bioreactor; trace organic contaminants; forward 37 osmosis; cellulose triacetate; polyamide. 


\section{Introduction}

39 Water reuse is a pragmatic strategy to ensure adequate water supplies and alleviate 40 water scarcity, which is a key issue hindering the sustainable development of our 41 society [1]. However, the ubiquitous presence of trace organic contaminants (TrOCs) 42 in reclaimed wastewater is often a major obstacle to water reuse. TrOCs, such as 43 endocrine disrupting and pharmaceutically active compounds, are derived from either anthropogenic or natural activities. Although TrOCs are present in the environment at trace concentrations, only ranging from a few nanograms per liter to several micrograms per liter, they would cause health risks to humans and other living organisms [2]. Thus, recent efforts have been dedicated to develop new or improve current technologies to increase TrOC removal and thereby advance wastewater treatment and reuse.

Osmotic membrane bioreactor (OMBR), which integrates forward osmosis (FO) with

51 biological treatment, has recently been developed for advanced wastewater treatment and reuse [3-8]. OMBR applications for nutrient recovery from waste streams have also been demonstrated in several recent studies [9, 10]. In OMBR, treated water is transported from the mixed liquor, through a semi-permeable FO membrane, into a highly concentrated draw solution (e.g. $\mathrm{NaCl}$ and seawater), with the osmotic pressure difference between these two solutions as the driving force. By using the osmotically driven FO process, OMBR also has lower membrane fouling propensity and higher fouling reversibility than conventional MBR that utilizes hydraulically driven membrane processes, such as microfiltration and ultrafiltration [3, 4]. Compared to conventional MBR that is widely deployed for non-potable water reuse, OMBR can

61 produce higher quality effluent due to the high rejection capacity of the FO membrane [11-13]. In particular, an additional desalination process, such as reverse osmosis (RO) or membrane distillation, is usually coupled with OMBR to regenerate the draw solution and further purify treated water suitable for potable reuse $[14,15]$. 
al. [16] reported that OMBR removed three pharmaceuticals, including naproxen, diclofenac, and ibuprofen, by more than $96 \%$. This result was consistent with that reported by Alturki et al. [17] who found that over $80 \%$ removal by OMBR was achieved for TrOCs with molecular weight larger than $266 \mathrm{~g} / \mathrm{mol}$; while the removal 70 of smaller compounds varied significantly depending on their intrinsic 71 biodegradability. Moreover, Holloway et al. [14] reported that 15 of 20 TrOCs detected in domestic wastewater were removed to below detection limit by OMBR and other five non-ionic hydrophobic chemicals (that were not highly removed) could be effectively retained by the subsequent RO process, which was used for draw solution regeneration and clean water production. It is noteworthy that all these studies utilized the asymmetric cellulose triacetate (CTA) FO membrane, which is featured with high water permeability and excellent fouling resistance due to the hydrophilic nature of cellulose [18].

With the development of new membrane materials and fabrication technologies, the polyamide thin film composite (TFC) FO membrane has been commercialized [19,

81 20]. The polyamide TFC FO membrane has higher water permeability, lower salt permeability, and better solute rejection in comparison with its CTA counterpart [21, 22]. The robust performance of OMBR using the TFC FO membrane for TrOC removal has been demonstrated by Luo et al. [23]. Since the CTA and TFC FO membranes are structurally and chemically different [24], it is necessary to compare comprehensively their performance in the biological reactor and thus provide important insight into membrane development for industrial OMBR applications. membrane; while inorganic fouling was more severe to the TFC membrane due to its higher salt rejection during OMBR operation. Nevertheless, the effect of these two

91 widely used FO membranes on the removal of TrOCs in OMBR is still unknown.

92 This study aimed to compare the performance between the CTA and TFC FO 93 membranes for OMBR application. A cross-flow RO process was integrated with each OMBR system to regenerate the draw solution and produce treated water. The 
integrated system was evaluated in terms of water production, salinity build-up in the bioreactor, biological stability, and contaminant (particularly TrOCs) removal. In addition, TrOC residuals in the sludge were examined in both OMBR systems. Results from this study provide important implications to the development of FO membranes for OMBR applications.

\section{Materials and methods}

\subsection{Synthetic wastewater and trace organic contaminants}

A synthetic wastewater, consisting of $100 \mathrm{mg} / \mathrm{L}$ glucose, $100 \mathrm{mg} / \mathrm{L}$ peptone, 17.5 $\mathrm{mg} / \mathrm{L} \mathrm{KH}_{2} \mathrm{PO}_{4}, 17.5 \mathrm{mg} / \mathrm{L} \mathrm{MgSO}_{4}, 10 \mathrm{mg} / \mathrm{L} \mathrm{FeSO}_{4}, 225 \mathrm{mg} / \mathrm{L} \mathrm{CH}_{3} \mathrm{COONa}$, and 35 $\mathrm{mg} / \mathrm{L}$ urea, was used in this study. Basic characteristics of the synthetic wastewater are shown in Table S1, Supplementary Data.

A set of 30 TrOCs were selected to represent emerging chemicals of significant concern. These compounds can be categorized as endocrine disrupting compounds, pharmaceutical and personal care products, industrial chemicals, and pesticides, which are ubiquitously present in municipal wastewater. Basic properties of the 30 TrOCs, including molecular weight, hydrophobicity, acid dissociation constant (pKa), and chemical structure, are shown in Table S2, Supplementary Data. A stock solution containing $25 \mu \mathrm{g} / \mathrm{mL}$ of each of TrOCs was prepared in pure methanol and stored at $-18{ }^{\circ} \mathrm{C}$ in the dark. The stock solution was added to the synthetic wastewater to obtain a concentration of $5 \mu \mathrm{g} / \mathrm{L}$ of each compound.

\subsection{Membranes}

Flat-sheet CTA and TFC FO membranes used for OMBR were supplied by Hydration Technology Innovations (HTI, Albany, OR). The CTA FO membrane consisted of an active layer made of cellulose triacetate and a polyester mesh for mechanical support. The TFC FO membrane comprised a polyamide active layer and a porous polysulfone supporting layer. A flat-sheet LFC3 membrane (Hydranautics, Oceanside, CA) made of polyamide was used in the RO system to re-concentrate the OMBR draw solution 
and produce treated water. Basic properties of these membranes are summarized in

123 Table S3, Supplementary Data.

124

128

130

\subsection{Experimental system}

Two identical, lab-scale OMBR-RO systems using different FO membranes were operated in parallel (Figure S1, Supplementary Data). Detail description of the OMBR-RO hybrid system has been reported in our previous study [26]. Briefly, this system was consisted of a wastewater reservoir, a biological reactor made of glass and housed a plate-and-frame FO membrane module, a draw solution tank, a cross-flow RO cell, and several pumps. The wastewater reservoir was placed on a digital balance, which was connected with a data logger to determine the OMBR water flux.

The FO membrane module was made of acrylic plastic and engraved a flow channel for the draw solution with a length, width, and height of $20 \mathrm{~cm}, 15 \mathrm{~cm}$, and $0.4 \mathrm{~cm}$, respectively. The FO membrane was sealed on the module surface with the active layer facing the mixed liquor (i.e. FO mode) and an effective area of $300 \mathrm{~cm}^{2}$. The RO membrane cell was made of stainless steel with a flow channel of $10 \mathrm{~cm}$ long, $4 \mathrm{~cm}$ wide, and $0.2 \mathrm{~cm}$ high. A temperature controller (Neslab RTE7, Waltham, MA) with a stainless steel heat exchanger coil was used to maintain the draw solution temperature. A digital flow meter (Optiflow, Palo Alto, CA) was connected to another data logger to record the RO water flux.

\subsection{Experimental protocol}

Each OMBR-RO system was inoculated with activated sludge collected from a conventional MBR, which had acclimatized to the synthetic wastewater and laboratory conditions for over 3 months and exhibited stable performance in terms of organic and nutrient removal. The mixed liquor suspended solid concentration (MLSS) was adjusted to approximately $5 \mathrm{~g} / \mathrm{L}$. Each bioreactor had an effective volume of $6 \mathrm{~L}$ and was continuously aerated to provide a dissolved oxygen (DO) concentration of above $2 \mathrm{mg} / \mathrm{L}$. The sludge retention time (SRT) was maintained at 20 days by daily withdrawing $300 \mathrm{~mL}$ mixed liquor. 
150 A $0.5 \mathrm{M} \mathrm{NaCl}$ solution was used as the OMBR draw solution and was circulated to

151 the FO membrane cell at a cross-flow velocity of $2.8 \mathrm{~cm} / \mathrm{s}$. At the same time, the draw

152 solution was pumped to the RO system with a cross-flow velocity of $41.7 \mathrm{~cm} / \mathrm{s}$. The

153 hydraulic pressure was adjusted daily to balance the water flux between the OMBR

154 and RO units, thereby maintaining the effective volume of the draw solution at $10 \mathrm{~L}$.

155 The draw solution temperature was maintained at $21 \pm 1{ }^{\circ} \mathrm{C}$, which was also the

156 controlled laboratory temperature. The two OMBR-RO systems were operated

157 continuously for 30 days without any membrane cleaning.

$158 \quad 2.5$ Analytical methods

$159 \quad$ 2.5.1 Basic water quality parameters

160 Dissolved organic carbon in aqueous samples was quantified by total organic carbon

161 (TOC) measurement. TOC and total nitrogen (TN) were analyzed using a TOC/TN 162 analyzer (TOC- $\mathrm{V}_{\mathrm{CSH}}$, Shimadzu, Kyoto). Ammonium $\left(\mathrm{NH}_{4}{ }^{+}\right)$and orthophosphate

$163\left(\mathrm{PO}_{4}{ }^{3-}\right)$ were measured by a Flow Injection Analysis system (QuikChem 8500, Lachat, 164 CO). An Orion 4-Star Plus pH/conductivity meter (Thermo Scientific, Waltham, MA)

165 was used to measure solution $\mathrm{pH}$ and electrical conductivity.

166 2.5.2 Analysis of trace organic contaminants

167 TrOC concentrations in aqueous samples were analyzed every six days based on the 168 method reported previously by Hai et al. [27]. This method included solid phase 169 extraction (SPE), derivatization, and measurement by a gas chromatography - mass 170 spectrometry system (QP5000 GC-MS, Shimadzu, Kyoto). During OMBR-RO 171 operation, TrOC removal by the bioreactor $\left(R_{B i o}\right)$, OMBR $\left(R_{O M B R}\right)$, and the overall

172 OMBR-RO system was defined as follow:

$173 \quad R_{\text {Bio }}=\left(1-\frac{C_{\text {Sup }} V_{B i o}+C_{\text {Draw }}^{*} \Delta V_{F O}}{C_{\text {Feed }} \Delta V}\right) \times 100 \%$

$174 R_{\text {OMBR }}=\left(1-\frac{C^{*}{ }_{\text {Draw }}}{C_{\text {Feed }}}\right) \times 100 \%$ 
$175 R_{\text {Overall }}=\left(1-\frac{C_{\text {Permeate }}}{C_{\text {Feed }}}\right) \times 100 \%$

176 where $C_{\text {Feed }}, C_{S u p}$, and $C_{\text {Permeate }}$ was the measured $\operatorname{TrOC}$ concentration in wastewater, 177 mixed liquor supernatant, and RO permeate, respectively; $C^{*}$ Draw was the TrOC

178 concentration in the FO permeate; $V_{B i o}$ was the effective bioreactor volume; and $\Delta V_{F O}$ 179 was the volume of water produced by FO between time $t$ and $t+\Delta t$. Some TrOCs 180 could accumulate in the draw solution if they passed through the FO but not the RO 181 membrane. Thus, $C^{*}$ Draw was calculated based on the mass balance:

$182 C_{\text {Draw }}^{*}=\frac{M_{F O}}{Q_{F O}}$

$183 \quad M_{F O}=\frac{V_{\text {Draw }}\left(C_{\text {Draw }(t+\Delta t)}-C_{\text {Draw }(t)}\right)}{\Delta t}+\frac{\frac{\left(C_{R O(t+\Delta t)}+C_{R O(t)}\right)}{2} \Delta V}{\Delta t}$

$184 \Delta V=Q_{R O} \Delta t$

185 where $M_{F O}$ was the mass flow rate of TrOCs that passed through the FO membrane; $186 C_{\operatorname{Draw}(t)}$ and $C_{\operatorname{Draw}(t+\Delta t)}$ was the measured TrOC concentration in the draw solution at 187 time $t$ and $t+\Delta t$, respectively; $C_{R O(t)}$ and $C_{R O(t+\Delta t)}$ was the measured $\operatorname{TrOC}$ 188 concentration in the RO permeate at time $t$ and $t+\Delta t$, respectively; and $Q_{F O}$ and $Q_{R O}$ 189 was the FO and RO water flux, respectively, which was adjusted to be equal as 190 described in Section 2.4. Based on eqs. (4) - (6), $C^{*}{ }_{\text {Draw }}$ was calculated as follows:

$$
C_{\text {Draw }}^{*}=\frac{V_{\text {Draw }}\left(C_{\text {Draw }(t+\Delta t)}-C_{\text {Draw }(t)}\right)}{\Delta V_{F O}}+\frac{\left(C_{R O(t+\Delta t)}+C_{R O(t)}\right)}{2}
$$

192 To quantify the contribution of the FO and RO membranes toward TrOC removal in 193 the OMBR-RO hybrid system, their observed rejections were calculated according to 194 eqs. (1) - (3):

195

$$
R_{O b F O}=R_{O M B R}-R_{B i o}
$$

$$
R_{\text {Ob RO }}=R_{\text {Overall }}-R_{\text {OMBR }}
$$


197 where $R_{O b F O}$ and $R_{O b R O}$ was the observed TrOC rejection by the FO and RO

198 membrane, respectively.

199 TrOC residuals in the sludge phase were also measured after being extracted 200 according to a solvent extraction method previously reported by Wijekoon et al. [28]. 201 Briefly, this method involved sludge drying by a Freeze Dryer (Alpha 1-2 LD, Christ $202 \mathrm{GmbH}$, Germany), ultrasonic solvent extraction using methanol and its blend with 203 dichloromethane $(1: 1, \mathrm{v} / \mathrm{v})$, respectively, following by SPE and subsequent 204 quantification using GC-MS as described for aqueous samples.

\section{$205 \quad$ 2.5.3 Biomass and membrane fouling characterization}

206 Sludge concentration was examined by measuing the MLSS and mixed liquor volatile 207 suspended solids (MLVSS) contents in the two bioreactors based on the Standard 208 Method 2540. Biomass activity was indicated by the specific oxygen uptake rate 209 (SOUR) of activated sludge, which was determined by the Standard Method 1683. 210 Extracellular polymeric substance (EPS) in the sludge was extracted using a method 211 descirbed by Zhang et al. [29]. EPS and soluble microbial products (SMP) in the 212 mixed liquor were measured by quantifying their protein and polysaccharide contents, 213 which were determined by the Folin method with bovine serum albumin as the 214 standard and the phenol-sulfuric acid method with glucose as the standard, 215 respectively [30].

216 The morphology and composition of both FO membrane surfaces were characterized 217 by a scanning electron microscopy (SEM) coupled with energy dispersive 218 spectroscopy (EDS) (JCM-6000, JEOL, Tokyo, Japan) at the end of OMBR operation.

219 Membrane samples were air-dried in a desiccator and then coated with an ultra-thin 220 gold layer with a sputter coater (SPI Module, West Chester, PA) for SEM imaging.

\section{Results and discussion}


223 A higher initial water flux was observed for OMBR using the polyamide TFC 224 membrane in comparison with that using the CTA membrane under the same 225 operating condition (Figure 1A). This result can be attributed to the different water 226 permeability coefficients (i.e. A values) of the two FO membranes. Based on the 227 standard protocol established by Cath et al. [21] to characterize FO membranes, the 228 water permeability of the TFC membrane was approximately three times higher than 229 that of the CTA membrane (Table S3, Supplementary Data).
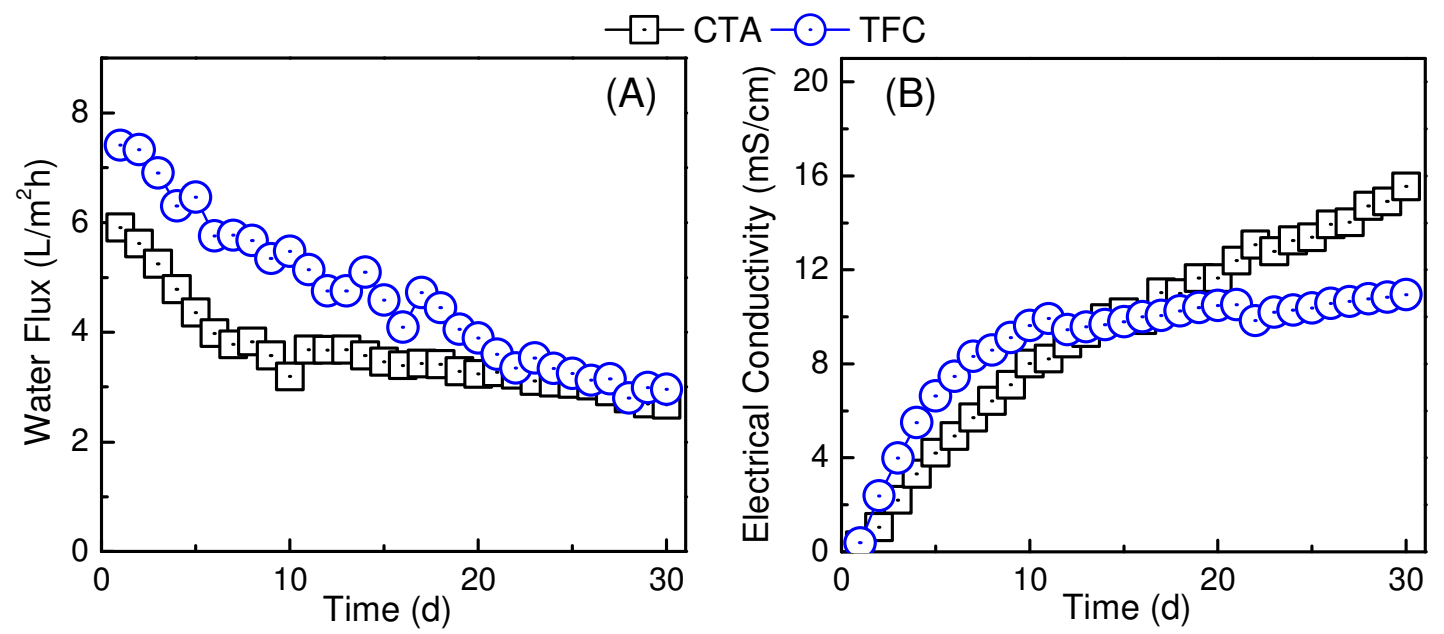

231 Figure 1: Water flux (A) and mixed liquor conductivity (B) during OMBR-RO 232 operation using the CTA and polyamide TFC FO membrane. Experimental conditions: $233 \mathrm{DO}=5 \mathrm{mg} / \mathrm{L}$; initial MLSS $=5.5 \mathrm{~g} / \mathrm{L} ; \mathrm{SRT}=20 \mathrm{~d}$; temperature $=22 \pm 1{ }^{\circ} \mathrm{C}$; draw 234 solution $=0.5 \mathrm{M} \mathrm{NaCl}$; draw cross-flow velocity $=2.8 \mathrm{~cm} / \mathrm{s} ; \mathrm{RO}$ cross-flow velocity $=$ $23541.5 \mathrm{~cm} / \mathrm{s}$.

236 Water flux of the OMBR system decreased continuously when using either TFC or 237 CTA FO membrane (Figure 1A). Since the draw solution salinity only decreased 238 slightly (Figure S2, Supplementary Data), the observed flux decline was mainly 239 attributed to salinity build-up in the bioreactor (Figure 1B) and membrane fouling 240 (Figure S3, Supplementary Data). Salinity build-up in the bioreactor is inherent to 241 OMBR due to the high salt rejection by the FO membrane and the reverse draw solute 242 flux [31]. The elevated salinity could increase the osmotic pressure in the mixed 243 liquor side and thus reduce the effective driving force (i.e. transmembrane osmotic 244 pressure) for water transport. On the other hand, despite the low fouling propensity of 
245 the FO membrane due to the absence of hydraulic pressure, a cake layer, mainly 246 consisting of carbon, oxygen, phosphorus, sodium, magnesium, and calcium, was 247 formed on both CTA and TFC membrane surfaces (Figure S3, Supplementary Data), 248 thereby reducing the water flux (Figure 1A).

249 The TFC membrane encountered a more dramatic flux decline compared to its CTA 250 counterpart (Figure 1A). This result can be attributed to the higher initial water flux 251 and the more significant increase in the bioreactor salinity when using the TFC 252 membrane (Figure 1). There is evidence that foulants accumulated on the FO 253 membrane surface could transition from a sparse and loose fouling layer at a low 254 initial permeate flux to a more compact and cohesive fouling layer at a high initial 255 permeate flux [32]. In addition, Mazlan et al. [24] also reported that the TFC FO 256 membrane was more susceptible to organic fouling than its CTA counterpart at the 257 same initial water flux, due to its relatively higher surface roughness and prominent 258 ridge-and-valley structure on the membrane surface. Foulants deposited on a rough 259 membrane surface could be shielded from air scouring or cross-flow shear force by 260 positive asperities and thus facilitate the development of a cohesive fouling layer [24, $26133]$. Indeed, a more homogenous and thick cake layer was observed on the TFC 262 membrane surface in comparison with that on the CTA membrane in this study 263 (Figure S3, Supplementary Data).

264 Salinity build-up in the bioreactor was more significant for the TFC membrane within 265 the first 10 days (Figure 1B), although it exhibited a lower salt permeability and thus a 266 smaller reverse salt flux than the CTA membrane (Table S3, Supplementary Data). 267 This observation was caused by the higher salt rejection of the TFC membrane (Table 268 S3, Supplementary Data). The higher bioreactor salinity encountered by the TFC 269 membrane could not only reduce the effective driving force for water transport, but 270 also lead to more severe membrane scaling and thus flux decline in comparison with 271 when the CTA membrane was used for OMBR. Although there were different 272 hydrodynamic conditions adjacent to the membrane surface, a higher salinity build-up 273 and more dramatic flux decline was also observed for the TFC membrane when these 
274 two FO membranes were compared in a side-stream OMBR system [25].

275 Nevertheless, the significant flux decline associated with the TFC membrane reduced 276 salinity build-up in the bioreactor, which was even lower than when the CTA 277 membrane was used from day 14 onward (Figure 1B).

\subsection{Biomass characteristics}

279 Different salinity profiles accompanied with the CTA and TFC membranes resulted in 280 discernible differences in biomass characteristics during OMBR operation (Figure 2). 281 It has been reported that the elevated salinity could inhibit microbial growth and 282 activity by causing cell plasmolysis before biological acclimatization to the saline 283 condition was achieved during OMBR operation [34, 35]. Indeed, an initial decrease 284 but subsequent increase in the biomass concentration (indicated by the MLSS and 285 MLVSS contents) and biological activity (suggested by the sludge SOUR) was 286 observed for both OMBR systems in this study (Figure 2A-C). Although the TFC 287 membrane resulted in more significant salinity build-up in the bioreactor than the 288 CTA membrane within the first two weeks (Figure 1B), there was no significant 289 difference between the two OMBR systems in terms of biomass concentration and 290 sludge activity. However, the MLVSS concentration decreased continuously in 291 OMBR using the CTA membrane (Figure 2B), possibly due to inadequate microbial 292 adaptation to the elevated saline condition, which was more severe than that using the 293 TFC membrane from day 14 onward (Figure 1B). 

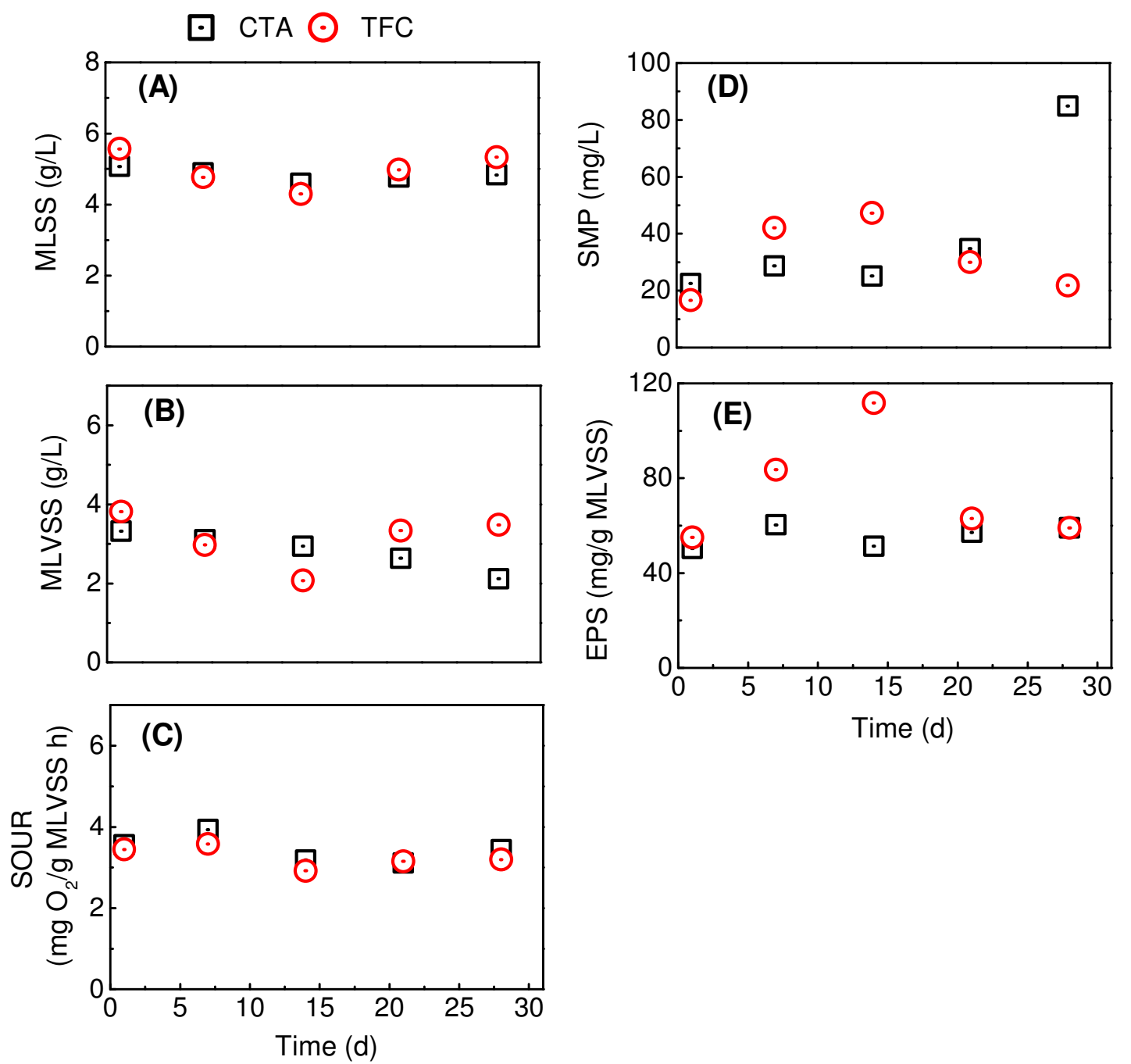

295 Figure 2: Biomass characteristics during OMBR operation using the CTA and 296 polyamide TFC FO membrane. Experimental conditions are shown in the caption of 297 Figure 1.

298 The saline condition can also increase the endogenous respiration of bacteria and thus 299 drive the secretion of organic cellular substances [34]. As mentioned above, the TFC 300 membrane caused more considerably saline condition to biomass than its CTA 301 counterpart within the first two weeks (Figure 1B). Thus, a more notable increase in 302 the SMP and EPS concentrations was observed for OMBR using the TFC membrane 303 (Figure 2D and E). With salinity build-up becoming less significant, the SMP and 304 EPS concentrations in the mixed liquor decreased gradually during OMBR operation 305 with the TFC membrane, and then stabilized at approximately $20 \mathrm{mg} / \mathrm{L}$ and $60 \mathrm{mg} / \mathrm{g}$ 306 MLVSS, respectively, from day 14 onward. By contrast, the bioreactor salinity 
307 increased continuously for OMBR using the CTA membrane (Figure 1B), remaining a

308 significant increase in the SMP concentration in the mixed liquor (Figure 2D).

309 Nevertheless, the EPS concentration was relatively stable along with salinity increase

310 in the bioreactor (Figure 2E), possibly due to its transition to SMP under saline

311 conditions [34].

\subsection{Removal of bulk organic matter and nutrients}

313 During OMBR-RO operation, no significant difference in TOC removal was observed

314 between the CTA and TFC FO membranes (Figure 3A and B). It has been well 315 established that the removal of organic matter in OMBR was driven by both 316 biological degradation and the rejection of the FO membrane [3]. Despite the 317 observed salinity build-up in the bioreactor, the two OMBR systems using different 318 FO membranes exhibited effective biodegradation of organic substances as indicated 319 by low TOC concentrations in both bioreactors. Nevertheless, compared to the CTA 320 membrane, a slightly higher TOC concentration in the bioreactor was observed when 321 using the TFC membrane (Figure 3A and B), possibly due to its higher rejection of 322 biologically persistent organic substances.

323 Although there was no significant difference in the overall $\mathrm{TN}$ removal by 324 OMBR-RO, its distribution in the hybrid system varied considerably when using 325 different FO membranes (Figure 3C and D). Compared to the CTA membrane, the 326 higher rejection capacity of the TFC membrane resulted in more significant TN 327 accumulation in the bioreactor, since $\mathrm{TN}$ removal was only dependent on the 328 biological assimilation with the absence of denitrification in the aerobic bioreactor 329 [36]. As a result, TN accumulation in the draw solution was more remarkable for 330 OMBR-RO using the CTA membrane, because some nitrogen species, mainly nitrate, 331 could permeate through the FO but was retained by the RO membrane [14]. 332 Regardless of the FO membrane type, TN accumulation in the draw solution 333 consequently reduced its overall removal by OMBR-RO and thus deteriorated the 334 product water quality. 
(A)

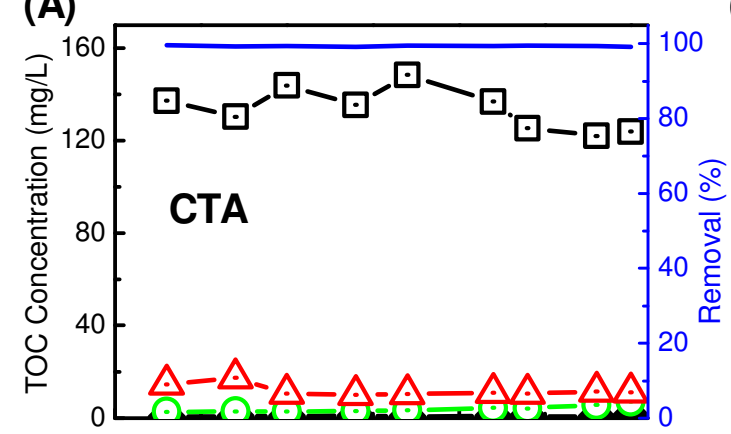

(C)

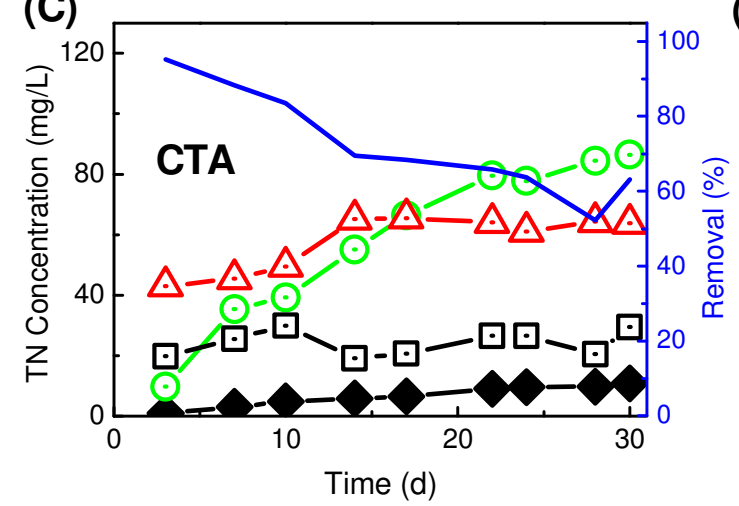

- RO Permeate - Removal

(B)

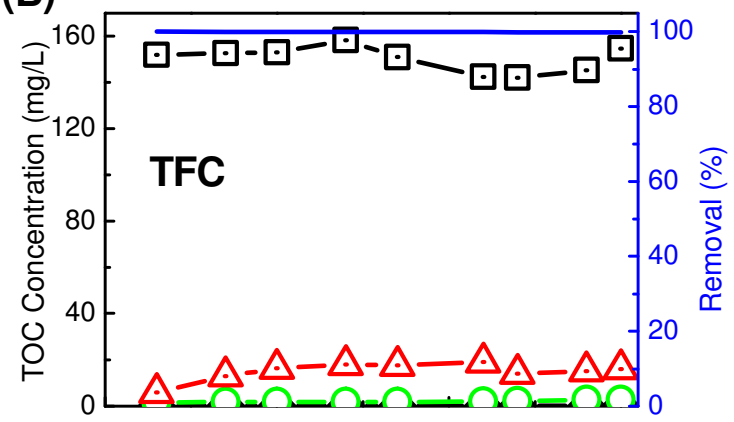

(D)

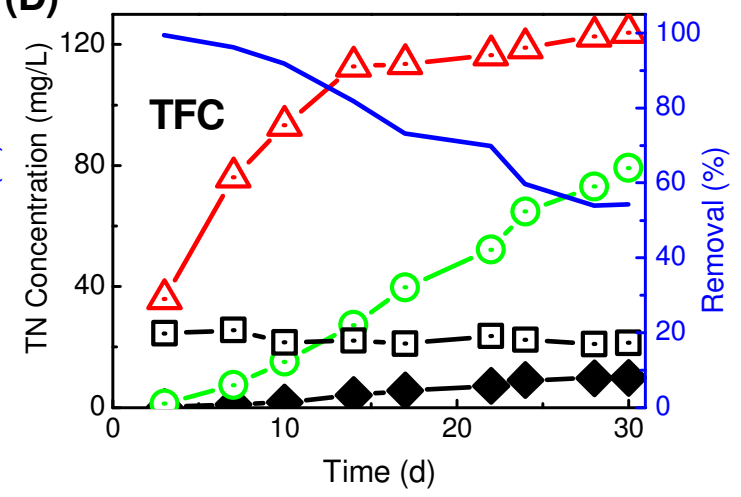

336 Figure 3: Distribution and removal of total organic carbon (TOC) (A and B) and total

337 nitrogen (TN) (C and D) in the OMBR-RO hybrid system using the CTA and 338 polyamide TFC FO membrane. Experimental conditions are given in the caption of 339 Figure 1.

340 Almost complete removal of nutrients was observed for OMBR-RO using either CTA 341 or TFC FO membrane (Figure 4). Negligible $\mathrm{NH}_{4}{ }^{+}$was detected in the two bioreactors, 342 indicating effective nitrification during OMBR operation regardless of the FO 343 membrane type (Figure $4 \mathrm{~A}$ and $\mathrm{B}$ ). However, $\mathrm{PO}_{4}{ }^{3-}$ accumulated considerably in the 344 two bioreactors (Figure 4C and D), due to its high rejection by both FO membranes 345 and low biological removal. It has been well established that $\mathrm{PO}_{4}{ }^{3-}$ removal by 346 activated sludge was only through microbial assimilation, particularly by 347 polyphosphate accumulating organisms, which are susceptible to the saline condition 348 [37]. On the other hand, the FO membrane can effectively reject phosphate ions since 349 they are negatively charged and have large hydrated radius [38]. Given its higher 350 rejection capacity and more negatively charged surface (Table S2, Supplementary 351 Data), the TFC membrane resulted in more $\mathrm{PO}_{4}{ }^{3-}$ accumulation in the bioreactor than 
352 the CTA membrane (Figure 4C and D). Nevertheless, both CTA and TFC membranes 353 enabled negligible nutrient accumulation in the draw solution during OMBR-RO 354 operation (Figure 4).

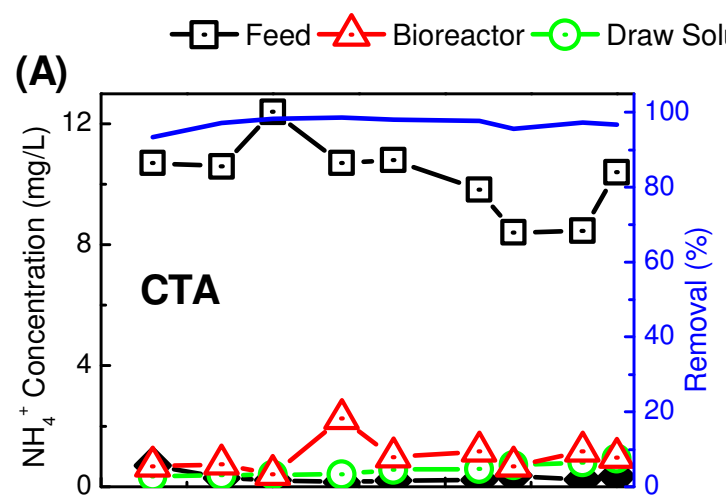

(C)

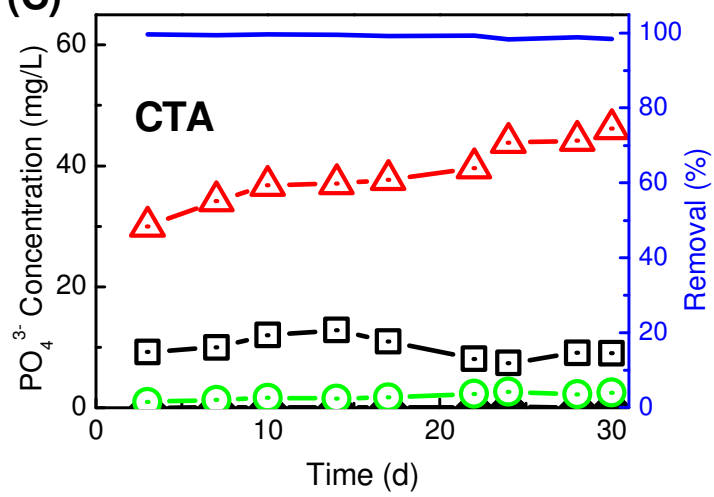

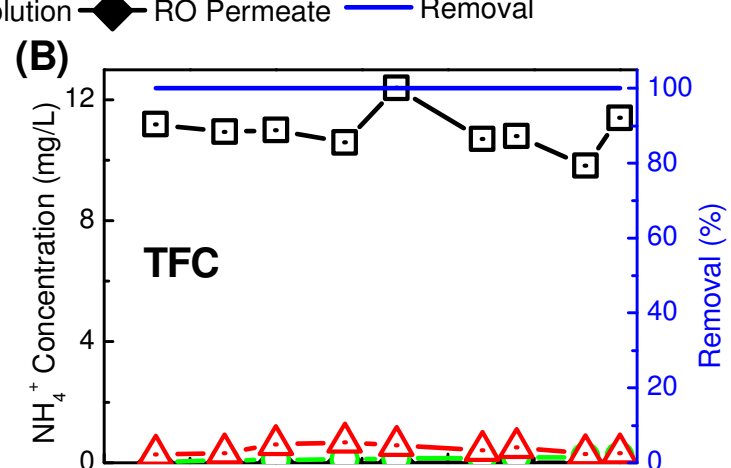

(D)

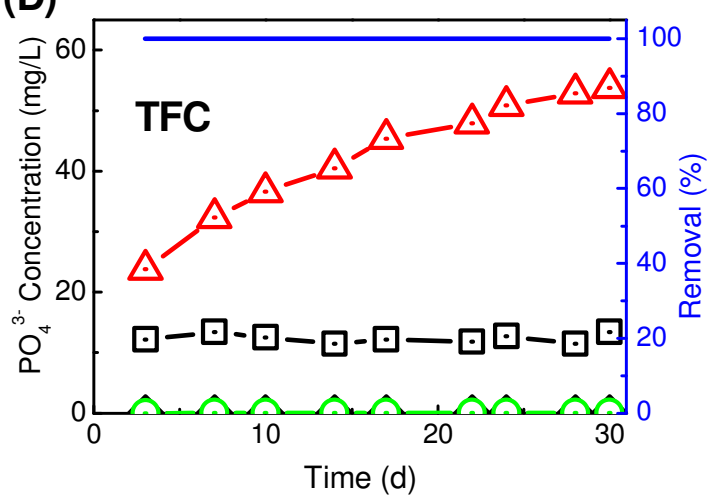

356 Figure 4: Distribution and overall removal of ammonia nitrogen $\left(\mathrm{NH}_{4}{ }^{+}\right)(\mathrm{A}$ and $\mathrm{B})$

357 and orthophosphate $\left(\mathrm{PO}_{4}{ }^{3-}\right)(\mathrm{C}$ and $\mathrm{D})$ in the OMBR-RO hybrid system using the 358 CTA and polyamide TFC membrane. Experimental conditions are given in the 359 caption of Figure 1.

\subsection{Removal of trace organic contaminants}

361 Based on their effective octanol - water partition coefficient (i.e. Log D) at the mixed 362 liquor $\mathrm{pH}$ of 8 , TrOCs selected in this study could be classified as hydrophilic (Log D 363 < 3.2) and hydrophobic ( $\log \mathrm{D}>3.2$ ) [39]. Generally, almost complete removal of all 36430 TrOCs by the OMBR-RO hybrid system was achieved when using either the CTA 365 or TFC FO membrane (Figure 5). This effective removal can be attributed to the 366 complementarity of the biological treatment and the dual high retention barriers 367 created by the FO and RO membranes. 


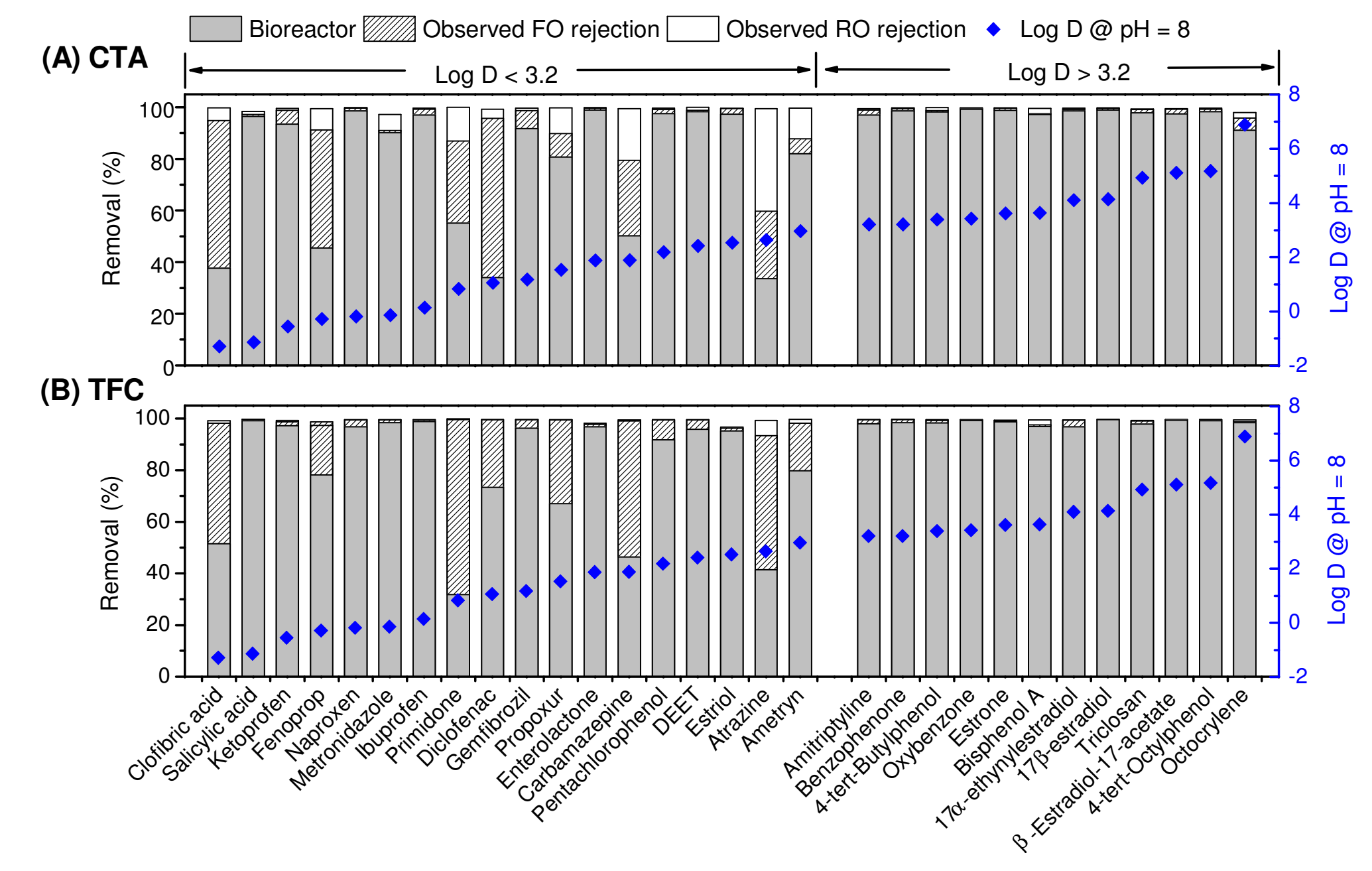


Figure 5: TrOC removal by the OMBR-RO hybrid system using the (A) CTA and (B) polyamide TFC FO membrane. Average removal data obtained from five measurements (once every six days) were demonstrated with standard deviation in the range of 0 to $20 \%$ (not shown in the Figure). TrOCs were ordered based on their

373 hydrophobicity indicated by the effective octanol - water partition coefficient (i.e.

$374 \log \mathrm{D})$ at $\mathrm{pH}$ 8. Observed TrOC rejection rates do not reflect the real separation 375 capacity of the membranes, but can quantify their contributions toward TrOC removal 376 in the hybrid system. Experimental conditions are as described in the caption of 377 Figure 1.

378 Of the 30 TrOCs investigated in this study, all 12 hydrophobic compounds (with Log 379 D > 3.2) were effectively removed from the two bioreactors (Figure 5). This result is 380 consistent with previous studies, where the effective removal of hydrophobic TrOCs 381 by activated sludge was attributed to their high adsorption onto biomass, which 382 therefore facilitated their biodegradation [28, 39]. As a result, the FO and RO 383 membranes did not significantly contribute toward the removal of these hydrophobic 384 TrOCs, as indicated by their negligible observed rejection rates (Figure 5). In other 385 words, the difference between the CTA and TFC FO membranes was insignificant 386 regarding the removal of these hydrophobic TrOCs in OMBR.

387 Effective removal from the two bioreactors (>95\%) was also observed for some 388 hydrophilic TrOCs (Figure 5). They were salicylic acid, ketoprofen, naproxen, 389 metronidazole, ibuprofen, gemfibrozil, enterolactone, pentachlorophenol, DEET, and 390 estriol. These 10 hydrophilic TrOCs were readily biodegradable, due to the presence 391 of strong electron donating functional groups (e.g. amine and hydroxyl) in the 392 molecular structure (Table S2, Supplementary Data) for enzymatic hydrolysis [39]. 393 Therefore, there was also no discernible difference between the two OMBR systems 394 for the removal of these hydrophilic and readily biodegraded TrOCs (Figure 5).

395 Several hydrophilic TrOCs were not well removed $(<80 \%)$ from the two bioreactors 396 (Figure 5). These compounds included clofibric acid, fenoprop, primidone, 397 diclofenac, propoxur, carbamazepine, atrazine, and ametryn. They have been referred 
to as biologically persistent chemicals due to their low removal by activated sludge, which could be further related to the presence of strong electron withdrawing

400 functional groups (e.g. chloro, amide, and nitro) in the molecular structure [28, 39]. 401 Nevertheless, the high retention barriers created by the FO (either CTA or TFC) and 402 subsequent RO membranes ensured more than $98 \%$ removal of these hydrophilic and 403 biologically persistent TrOCs by OMBR-RO (Figure 5).

404 Compared to the CTA membrane, the TFC membrane exhibited more contribution 405 toward the removal of hydrophilic and biologically persistent TrOCs in OMBR 406 (Figure 5). This result could be attributed to the higher rejection of these compounds 407 by the TFC membrane. The TFC membrane with polyamide active layer was more 408 negatively charged than the CTA membrane (Table S1, Supplementary Data). Thus, 409 the TFC membrane could enhance the rejection of negatively charged hydrophilic 410 TrOCs (e.g. clofibric acid and fenoprop) with $\mathrm{pKa}<8$ (i.e. the mixed liquor $\mathrm{pH}$ ) by 411 electrostatic repulsion (Figure 5). In addition, pore hydration induced by membrane 412 surface charge could also result in higher TrOC rejection by the TFC membrane. Pore 413 hydration is caused by the permanent attachment of a layer of water molecules to the 414 negatively charged membrane surface via hydrogen bonding and thus could narrow 415 the effective membrane pore size [40]. It has been reported that the TFC membrane 416 encountered more pore hydration than the CTA membrane due to its more surface 417 charge and less reverse salt flux [22], since the higher reverse salt flux could increase 418 the ionic strength within the membrane pores and thereby suppress pore hydration 419 [41]. Therefore, although the TFC membrane had a larger pore size and molecular 420 weight cut-off (Table S2, Supplementary Data), it exhibited a higher rejection of 421 TrOCs (either ionic or non-ionic) by steric hindrance than the CTA membrane. Steric 422 hindrance could be more notable for the rejection of ionic TrOCs $(\mathrm{pKa}<$ mixed liquor $423 \mathrm{pH})$ (Table S2, Supplementary Data), because they were hydrated and their hydrated 424 radii were significantly larger than their apparent radii in the mixed liquor [41].

425 The higher rejection capacity of the TFC membrane led to almost complete removal 426 of all hydrophilic and recalcitrant TrOCs in OMBR and thus reduced the rejection 
stress of the downstream RO membrane when compared to the CTA membrane (Figure 5). It has been reported that TrOCs could accumulate in the draw solution and consequently deteriorate the product water quality if they could pass through the FO membrane, but was retained by the RO membrane in FO-RO applications [42]. Indeed, a much more considerable accumulation of TrOCs in the draw solution was observed in this study when the CTA membrane was used for OMBR-RO in comparison with that using the TFC membrane (Figure S4, Supplementary Data). This result suggests that the deployment of highly selective FO membranes in the OMBR-RO hybrid system would reduce the purification of the draw solution (e.g. by advanced oxidization process and activated carbon adsorption) to secure the high product water quality and system sustainability.

\subsection{Residues of trace organic contaminants in the sludge}

TrOC residuals in the sludge varied considerably at the end of OMBR operation using either the CTA or TFC FO membrane (Figure 6). Of the 30 TrOCs selected in this study, relatively low accumulation in the sludge was observed for most hydrophilic compounds ( $\log \mathrm{D}<3.2$ ), given their weak hydrophobic interaction with biosolids [43]. Some hydrophilic TrOCs, such as carbamazepine and pentachlorophenol, resided significantly in the sludge in both bioreactors. Similar results were also observed during conventional MBR operation and could be attributed to their moderate hydrophobicity and relatively low biodegradability [28, 44]. Although hydrophobic TrOCs absorbed easily on biosolids, their residuals in the sludge was insignificant with amitriptyline as the only exception (Figure 6). This result was caused by the high biodegradability of these hydrophobic TrOCs and their favorable adsorption onto biosolids, which in turn facilitated their biodegradation [43]. The high content of amitriptyline in the sludge was observed, because of both the hydrophobic and electrostatic interactions between this positively charged compound and negatively charged biosolids [45].

Of the 30 TrOCs selected in this study, 14 compounds accumulated more significantly 
455 in the sludge when the CTA membrane was used in comparison with the TFC

456 membrane (Figure 6). This observation was possibly due to the higher bioreactor 457 salinity at the end of OMBR operation when the CTA membrane was used (Figure 458 1B). The elevated salinity could increase the sludge hydrophobicity [34] and thus 459 enhance the hydrophobic interaction with TrOCs. By contrast, six TrOCs exhibited 460 considerably higher accumulation in the sludge when the TFC membrane was used 461 (Figure 6). They were carbamazepine, pentachlorophenol, atrazine, ametryn, 462 amitriptyline, 4-tert-octylphenol, and octocrylene. These compounds were moderately 463 or highly hydrophobic and could be effectively rejected by the TFC FO membrane, 464 thereby increasing adsorption onto biosolids. Thus, further attention should be paid on 465 the removal of these TrOCs, especially these that are biologically persistent, in the 466 management of waste sludge from OMBR using highly selective FO membranes. 


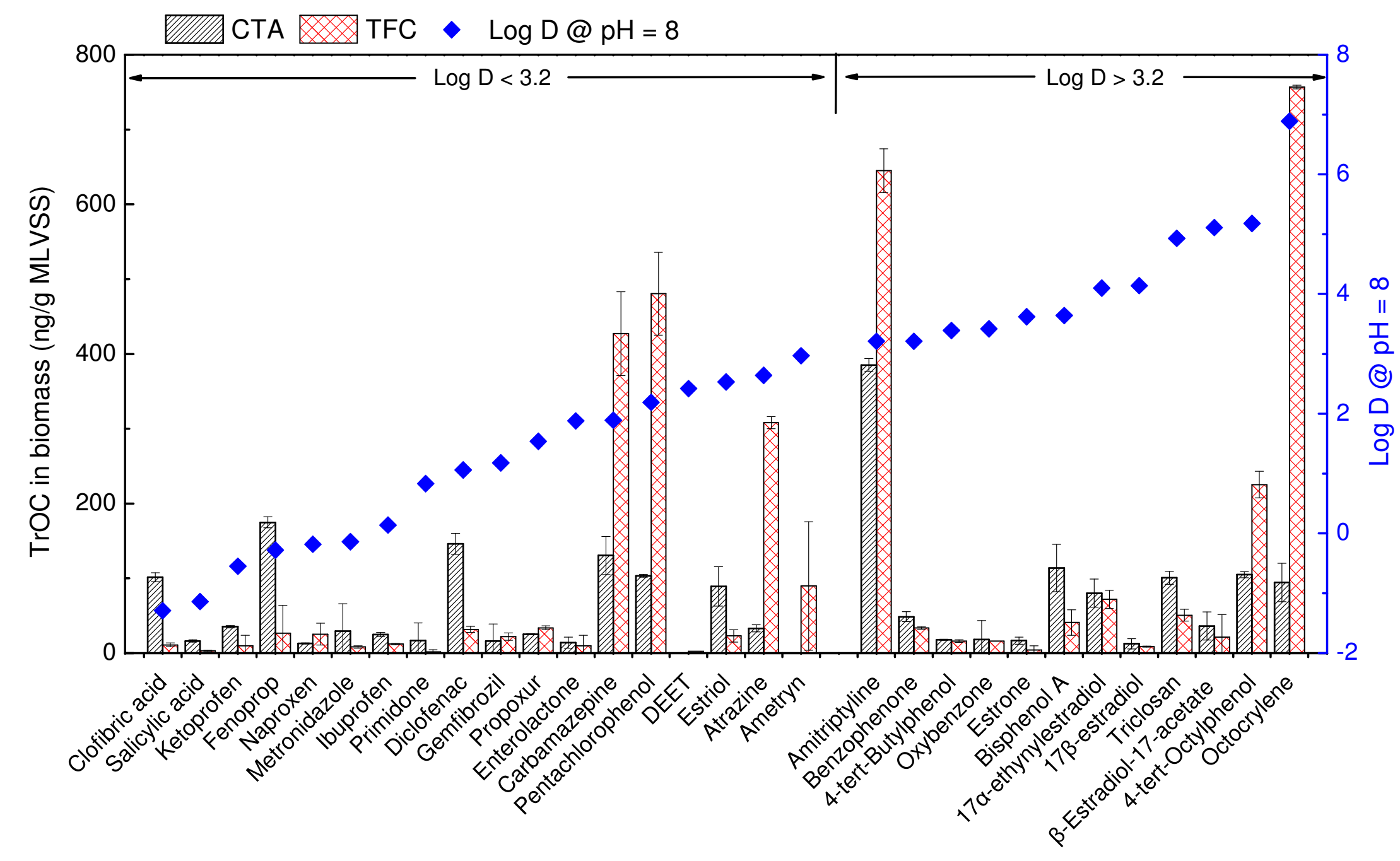


468 Figure 6: TrOC residues in the sludge phase at the end of OMBR-RO operation using 469 the CTA and polyamide TFC FO membrane. Error bars represent standard deviation 470 from two sludge samples taken from each bioreactor. Experimental conditions are as 471 described in the caption of Figure 1.

\section{Conclusion}

473 Results reported here show that the TFC membrane produced higher initial water flux 474 but more significant flux decline than the CTA membrane in OMBR operation. A 475 higher but subsequently lower salinity build-up in the bioreactor was observed for 476 OMBR using the TFC membrane compared to its CTA counterpart, which thereby 477 caused considerable differences in sludge characteristics. All 30 TrOCs selected in 478 this study were effectively removed by the hybrid OMBR-RO system using either the 479 CTA or TFC membrane. Nevertheless, the TFC membrane contributed more 480 contribution toward the removal of hydrophilic and biologically persistent TrOCs than 481 the CTA membrane and thus reduced their accumulation in the draw solution in 482 OMBR-RO. In addition, these two FO membrane types also resulted in different 483 TrOC accumulation in the sludge during OMBR operation.

\section{Acknowledgements}

485 This research was supported under Australian Research Council's Discovery Project 486 funding scheme (project DP140103864) and Science \&Technology Planning Project 487 of Guizhou Academy of Agricultural Science (project 2014-014). Dr. Jinguo Kang is 488 thanked for TrOC analysis.

\section{6. References}

490 [1] M.A. Shannon, P.W. Bohn, and M. Elimelech, Science and technology for water 491 purification in the coming decades. Nature, 2008, 452: 301-310.

492 [2] Y.L. Luo, W.S. Guo, H.H. Ngo, L.D. Nghiem, F.I. Hai, J. Zhang, S. Liang, and 493 X.C.C. Wang, A review on the occurrence of micropollutants in the aquatic 494 environment and their fate and removal during wastewater treatment. Sci. Total 
Environ., 2014, 473: 619-641.

496 [3] A. Achilli, T.Y. Cath, E.A. Marchand, and A.E. Childress, The forward osmosis membrane bioreactor: A low fouling alternative to MBR processes. Desalination,

499 [4] E.R. Cornelissen, D. Harmsen, E.F. Beerendonk, J.J. Qin, H. Oo, K.F. De Korte, 500 and J.W.M.N. Kappelhof, The innovative osmotic membrane bioreactor (OMBR) 501 for reuse of wastewater. Water Sci. Technol., 2011, 63(8): 1557-1565.

502 [5] L. Chen, Y. Gu, C. Cao, J. Zhang, J.W. Ng, and C. Tang, Performance of a 503 submerged anaerobic membrane bioreactor with forward osmosis membrane for 504 low-strength wastewater treatment. Water Res., 2014, 50: 114-123.

505 [6] B. Aftab, S.J. Khan, T. Maqbool, and N.P. Hankins, High strength domestic 506 wastewater treatment with submerged forward osmosis membrane bioreactor. $507 \quad$ Water Sci. Technol., 2015, 72(1): 141-149.

508 [7] N.C. Nguyen, S.S. Chen, H.T. Nguyen, S.S. Ray, H.H. Ngo, W. Guo, and P.H. Lin, 509 Innovative sponge-based moving bed-osmotic membrane bioreactor hybrid 510 system using a new class of draw solution for municipal wastewater treatment. $511 \quad$ Water Res., 2016, 91: 305-313.

512 [8] Y. Kim, L. Chekli, W.-G. Shim, S. Phuntsho, S. Li, N. Ghaffour, T. Leiknes, and 513 H.K. Shon, Selection of suitable fertilizer draw solute for a novel fertilizer-drawn 514 forward osmosis-anaerobic membrane bioreactor hybrid system. Bioresour. $515 \quad$ Technol., 2016, 210: 26-34.

516 [9] L. Huang, D.J. Lee, and J.Y. Lai, Forward osmosis membrane bioreactor for 517 wastewater treatment with phosphorus recovery. Bioresour. Technol., 2015, 198: $518 \quad 418-423$.

519 [10] W. Luo, F.I. Hai, W.E. Price, W. Guo, H.H. Ngo, K. Yamamoto, and L.D. Nghiem, 520 Phosphorus and water recovery by a novel osmotic membrane bioreactor-reverse 521 osmosis system. Bioresour. Technol., 2016, 200: 297-304.

522 [11] A.A. Alturki, J.A. McDonald, S.J. Khan, W.E. Price, L.D. Nghiem, and M. 
Elimelech, Removal of trace organic contaminants by the forward osmosis process. $524 \quad$ Sep. Purif. Technol., 2013, 103: 258-266.

[12] R.W. Holloway, A. Achilli, and T.Y. Cath, The osmotic membrane bioreactor: A critical review. Environ. Sci.: Water Res. Technol., 2015, 1(5): 581-605.

[13] X. Wang, V.W.C. Chang, and C.Y. Tang, Osmotic membrane bioreactor (OMBR) technology for wastewater treatment and reclamation: Advances, challenges, and prospects for the future. J. Membr. Sci., 2016, 504: 113-132.

530 [14] R.W. Holloway, J. Regnery, L.D. Nghiem, and T.Y. Cath, Removal of trace organic chemicals and performance of a novel hybrid ultrafiltration-osmotic membrane bioreactor. Environ. Sci. Technol., 2014, 48(18): 10859-10868.

[15] N.C. Nguyen, H.T. Nguyen, S.S. Chen, H.H. Ngo, W. Guo, W.H. Chan, S.S. Ray,

[16] W.C.L. Lay, Q. Zhang, J. Zhang, D. McDougald, C. Tang, R. Wang, Y. Liu, and A.G. Fane, Effect of pharmaceuticals on the performance of a novel osmotic membrane bioreactor (OMBR). Sep. Purif. Technol., 2012, 47(4): 543-554.

[17] A.A. Alturki, J. McDonald, S.J. Khan, F.I. Hai, W.E. Price, and L.D. Nghiem, Performance of a novel osmotic membrane bioreactor (OMBR) system: Flux stability and removal of trace organics. Bioresour. Technol., 2012, 113: 201-206.

[18] J.R. McCutcheon and M. Elimelech, Influence of membrane support layer hydrophobicity on water flux in osmotically driven membrane processes. J. Membr. Sci., 2008, 318(1): 458-466.

[19] J. Ren and J.R. McCutcheon, A new commercial thin film composite membrane for forward osmosis. Desalination, 2014, 343: 187-193.

[20] A.G. Fane, R. Wang, and M.X. Hu, Synthetic Membranes for Water Purification: Status and Future. Angew. Chem. Int. Ed., 2015.

[21] T.Y. Cath, N.T. Hancock, J. Lampi, L.D. Nghiem, M. Xie, N.Y. Yip, M. 

A.E. Childress, and I.V. Farr, Standard methodology for evaluating membrane performance in osmotically driven membrane processes. Desalination, 2013, 312: 31-38.

[22] M. Xie, L.D. Nghiem, W.E. Price, and M. Elimelech, Relating rejection of trace organic contaminants to membrane properties in forward osmosis: Measurements, modelling and implications. Water Res., 2014, 49: 265-274.

[23] W. Luo, H.V. Phan, M. Xie, F.I. Hai, W.E. Price, M. Elimelech, and L.D. Nghiem,

[24] N.M. Mazlan, P. Marchetti, H.A. Maples, B. Gu, S. Karan, A. Bismarck, and A.G. Osmotic versus conventional membrane bioreactors integrated with reverse osmosis for water reuse: Biological stability, membrane fouling, and contaminant removal. Water Res., 2017, 109: 122-134. Livingston, Organic fouling behaviour of structurally and chemically different forward osmosis membranes - A study of cellulose triacetate and thin film composite membranes. J. Membr. Sci., 2016, 520: 247-261.

[25] X. Wang, Y. Zhao, B. Yuan, Z. Wang, X. Li, and Y. Ren, Comparison of biofouling mechanisms between cellulose triacetate (CTA) and thin-film composite (TFC) polyamide forward osmosis membranes in osmotic membrane bioreactors. Bioresour. Technol., 2016, 202: 50-58.

[26] W. Luo, F.I. Hai, W.E. Price, M. Elimelech, and L.D. Nghiem, Evaluating ionic organic draw solutes in osmotic membrane bioreactors for water reuse. J. Membr.

576 [28] K.C. Wijekoon, F.I. Hai, J. Kang, W.E. Price, W. Guo, H.H. Ngo, and L.D. 577 Nghiem, The fate of pharmaceuticals, steroid hormones, phytoestrogens, 578 UV-filters and pesticides during MBR treatment. Bioresour. Technol., 2013, 144: 
580 [29] X. Zhang, P.L. Bishop, and B.K. Kinkle, Comparison of extraction methods for 581 quantifying extracellular polymers in biofilms. Water Sci. Technol., 1999, 39(7): $582 \quad 211-218$.

583 [30] G.U. Semblante, F.I. Hai, H. Bustamante, N. Guevara, W.E. Price, and L.D. 584 Nghiem, Effects of iron salt addition on biosolids reduction by 585 oxic-settling-anoxic (OSA) process. Int. Biodeterior. Biodegrad., 2015, 104: $586 \quad 391-400$.

587 [31] W. Luo, F.I. Hai, W.E. Price, W. Guo, H.H. Ngo, K. Yamamoto, and L.D. Nghiem, 588 High retention membrane bioreactors: Challenges and opportunities. Bioresour. $589 \quad$ Technol., 2014, 167: 539-546.

590 [32] M. Xie, L.D. Nghiem, W.E. Price, and M. Elimelech, Impact of organic and 591 colloidal fouling on trace organic contaminant rejection by forward osmosis: Role 592 of initial permeate flux. Desalination, 2014, 336(1): 146-152.

593 [33] E.M.V. Hoek, S. Bhattacharjee, and M. Elimelech, Effect of Membrane Surface 594 Roughness on Colloid-Membrane DLVO Interactions. Langmuir, 2003, 19(11): 595 4836-4847.

596 [34] W.C.L. Lay, Y. Liu, and A.G. Fane, Impacts of salinity on the performance of 597 high retention membrane bioreactors for water reclamation: A review. Water Res., $598 \quad 2010,44(1): 21-40$.

599 [35] W. Luo, H.V. Phan, F.I. Hai, W.E. Price, W. Guo, H.H. Ngo, K. Yamamoto, and 600 L.D. Nghiem, Effects of salinity build-up on the performance and bacterial 601 community structure of a membrane bioreactor. Bioresour. Technol., 2016, 200: $602 \quad 305-310$.

603 [36] L.N. Nguyen, F.I. Hai, J. Kang, W.E. Price, and L.D. Nghiem, Removal of 604 emerging trace organic contaminants by MBR-based hybrid treatment processes. 605 Int. Biodeterior. Biodegrad., 2013, 85: 474-482.

606 [37] R.J. Seviour, T. Mino, and M. Onuki, The microbiology of biological phosphorus 
removal in activated sludge systems. FEMS Microbiol. Rev. , 2003, 27(1): 99-127.

608 [38] R.W. Holloway, A.E. Childress, K.E. Dennett, and T.Y. Cath, Forward osmosis 609 for concentration of anaerobic digester centrate. Water Res., 2007, 41(17): $610 \quad 4005-4014$

611 [39] N. Tadkaew, F.I. Hai, J.A. McDonald, S.J. Khan, and L.D. Nghiem, Removal of 612 trace organics by MBR treatment: The role of molecular properties. Water Res., $613 \quad 2011,45(8): 2439-2451$.

614 [40] A.V. Raghunathan and N.R. Aluru, Molecular Understanding of Osmosis in 615 Semipermeable Membranes. Phys. Rev. Lett, 2006, 97(2): 024501.

616 [41] L.D. Nghiem, A.I. Schäfer, and M. Elimelech, Role of electrostatic interactions in 617 the retention of pharmaceutically active contaminants by a loose nanofiltration 618 membrane. J. Membr. Sci., 2006, 286(1-2): 52-59.

619 [42] A. D'Haese, P. Le-Clech, S. Van Nevel, K. Verbeken, E.R. Cornelissen, S.J. Khan, 620 and A.R.D. Verliefde, Trace organic solutes in closed-loop forward osmosis 621 applications: Influence of membrane fouling and modeling of solute build-up. 622 Water Res., 2013, 47(14): 5232-5244.

623 [43] G.U. Semblante, F.I. Hai, X. Huang, A.S. Ball, W.E. Price, and L.D. Nghiem, 624 Trace organic contaminants in biosolids: Impact of conventional wastewater and 625 sludge processing technologies and emerging alternatives. J. Hazard. Mater. , 2015, 626 300: $1-17$.

627 [44] W.H. Luo, F.I. Hai, J.G. Kang, W.E. Price, W.S. Guo, H.H. Ngo, K. Yamamoto, 628 and L.D. Nghiem, Effects of salinity build-up on biomass characteristics and trace 629 organic chemical removal: Implications on the development of high retention 630 membrane bioreactors. Bioresour. Technol., 2015, 177: 274-281.

631 [45] J. Stevens-Garmon, J.E. Drewes, S.J. Khan, J.A. McDonald, and E.R.V. 632 Dickenson, Sorption of emerging trace organic compounds onto wastewater 633 sludge solids. Water Res., 2011, 45(11): 3417-3426. 
Osmotic membrane bioreactors for wastewater reuse: Performance comparison between cellulose triacetate and polyamide thin film composite membranes

638

\section{Supplementary Data}

640

641

642

643

Bangxi Zhang ${ }^{\mathrm{a} b}$, Xiaoye Song ${ }^{\mathrm{c}}$, Long D. Nghiem ${ }^{\mathrm{c}}$, Guoxue Li ${ }^{\mathrm{a}}$, Wenhai Luo ${ }^{\mathrm{a}^{*}}$

$644{ }^{a}$ Beijing Key Laboratory of Farmland Soil Pollution Prevention and Remediation, 645 College of Resources and Environmental Sciences, China Agricultural University, 646 Beijing, 100193, China

$647{ }^{b}$ Guizhou Institute of Agricultural Resources and Environment, Guiyang, Guizhou, 648 550001, China

649

${ }^{c}$ Strategic Water Infrastructure Laboratory, School of Civil, Mining and

650 Environmental Engineering, University of Wollongong, Wollongong, NSW 2522,

* Corresponding author: luowenhai@ cau.edu.cn; Ph: +86 18311430503. 


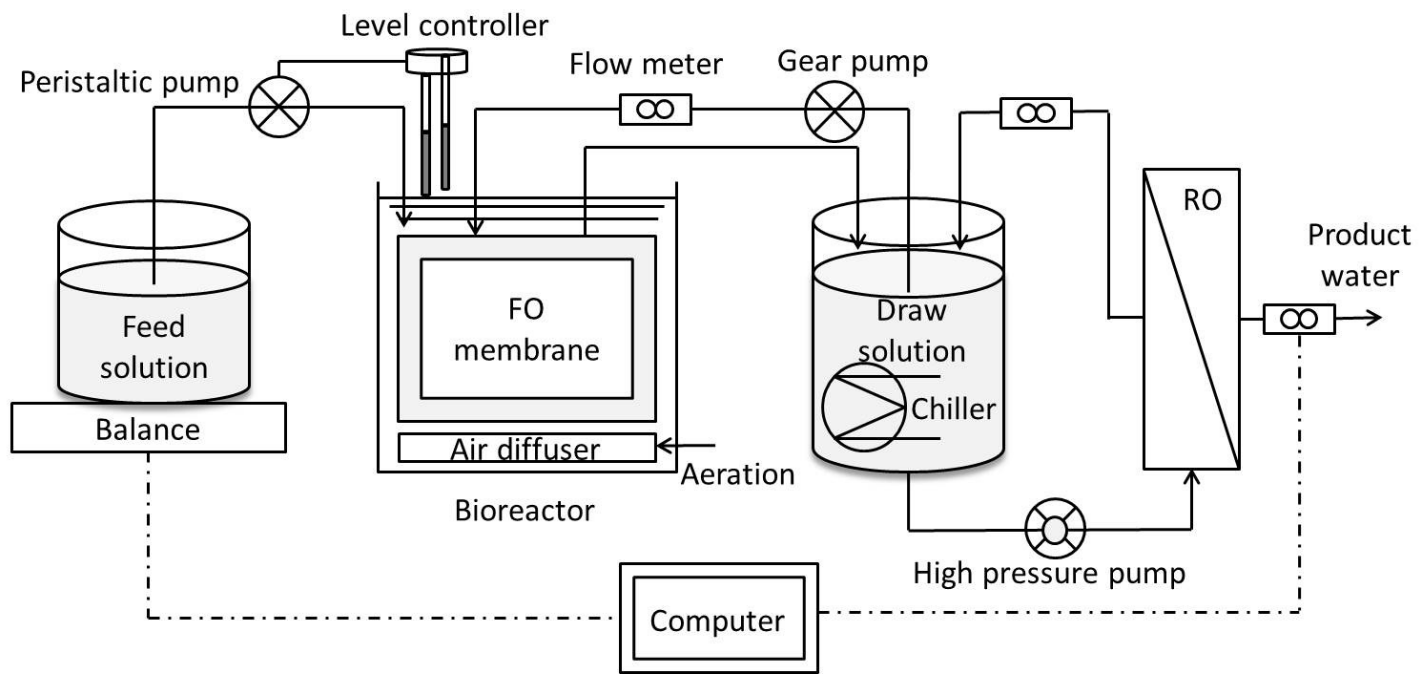

653 Figure S1: Schematic diagram of the OMBR-RO system used in this study.

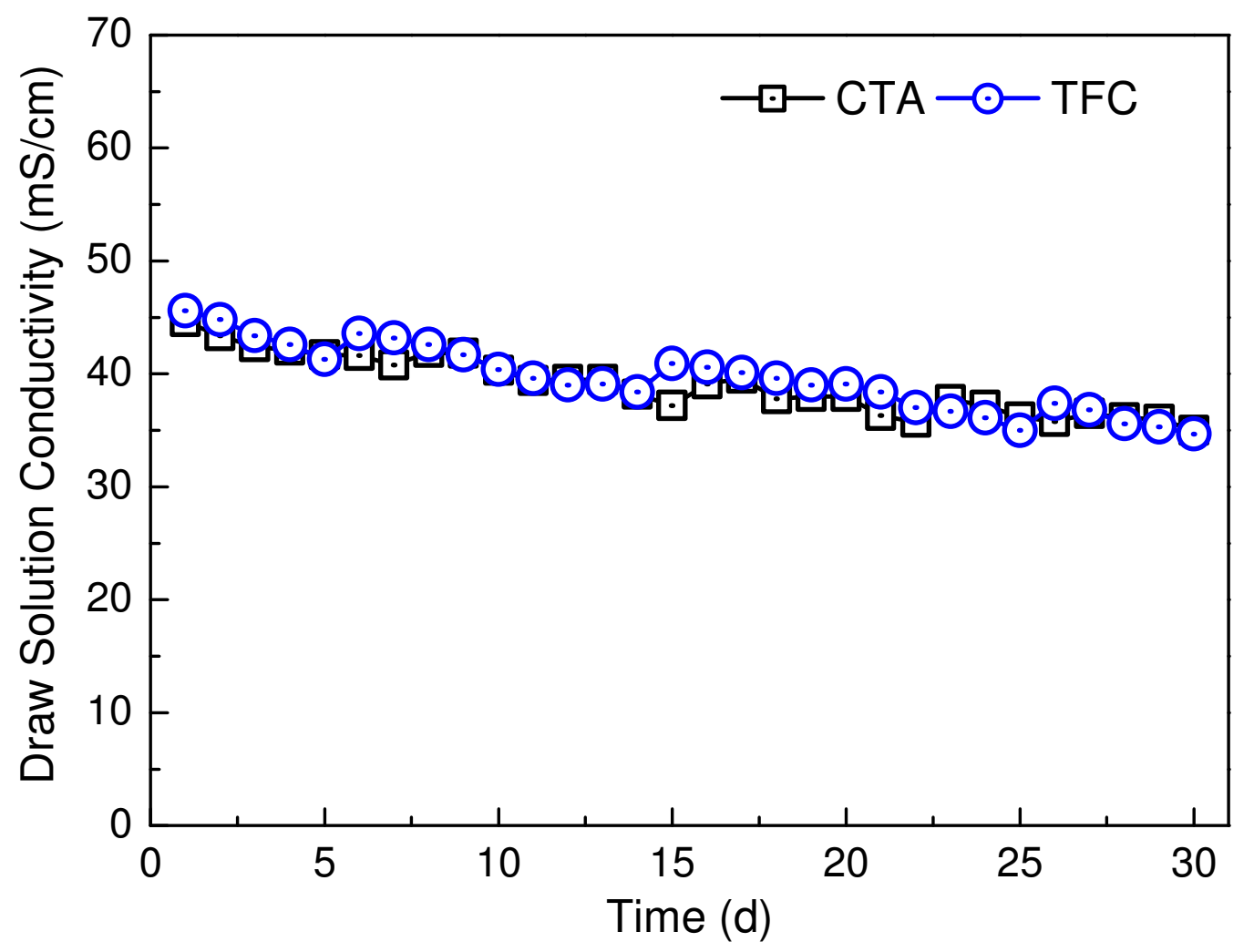

655 Figure S2: Electrical conductivity of the draw solutions during OMBR operation 656 using the CTA and polyamide TFC FO membranes. Experimental conditions: DO = 5 $657 \mathrm{mg} / \mathrm{L} ;$ initial MLSS $=5.5 \mathrm{~g} / \mathrm{L} ; \mathrm{SRT}=20 \mathrm{~d}$; temperature $=22 \pm 1{ }^{\circ} \mathrm{C}$; draw solution $=$ $6580.5 \mathrm{M} \mathrm{NaCl}$; draw cross-flow velocity $=2.8 \mathrm{~cm} / \mathrm{s} ; \mathrm{RO}$ cross-flow velocity $=41.5$ $659 \mathrm{~cm} / \mathrm{s}$. 

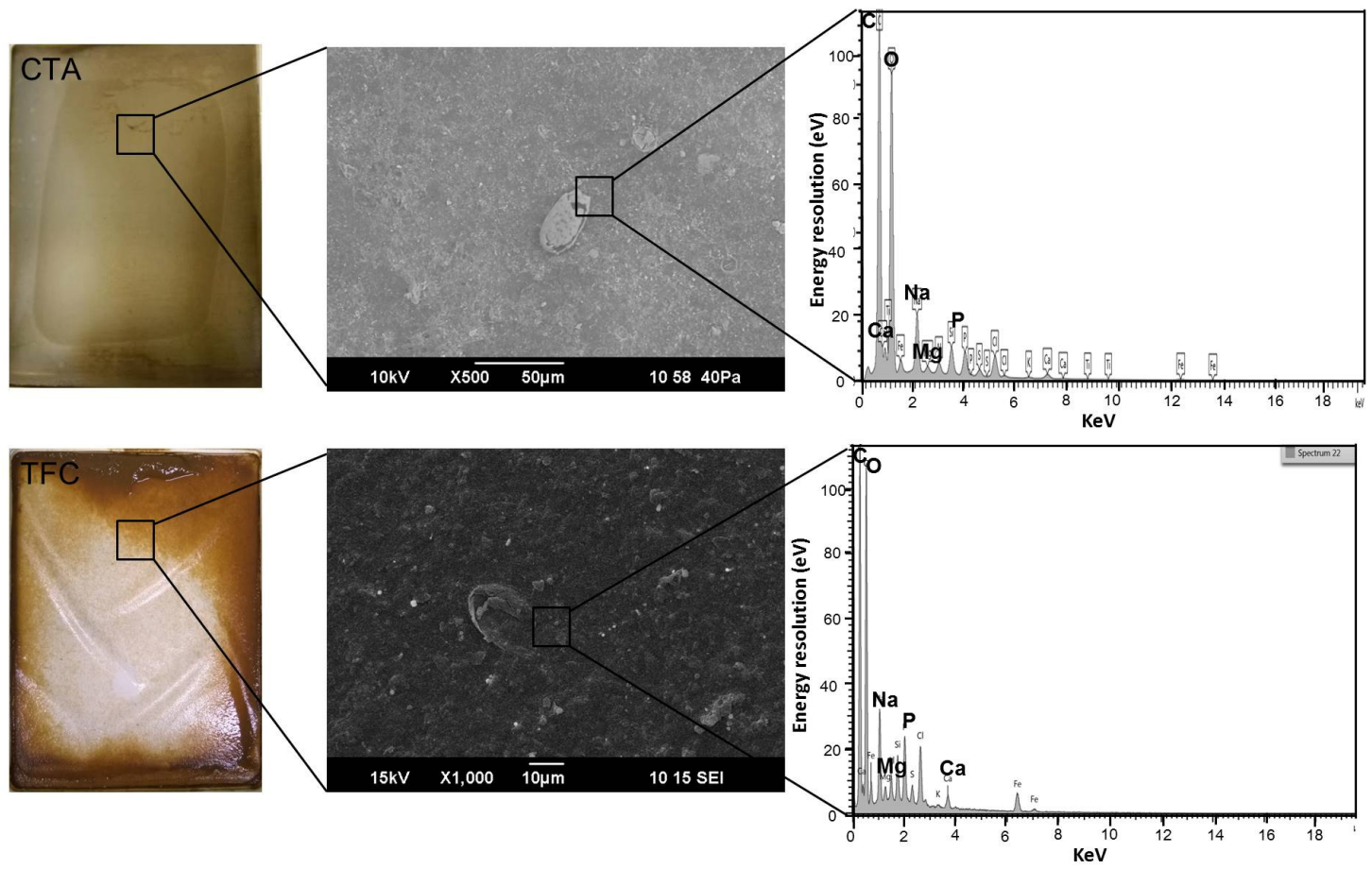

661

662 Figure S3: Photos, SEM images, and EDS measurements of the CTA and polyamide 663 TFC FO membranes after 30 days of OMBR-RO operation. Experimental conditions 664 are shown in the caption of Figure S2.

665 


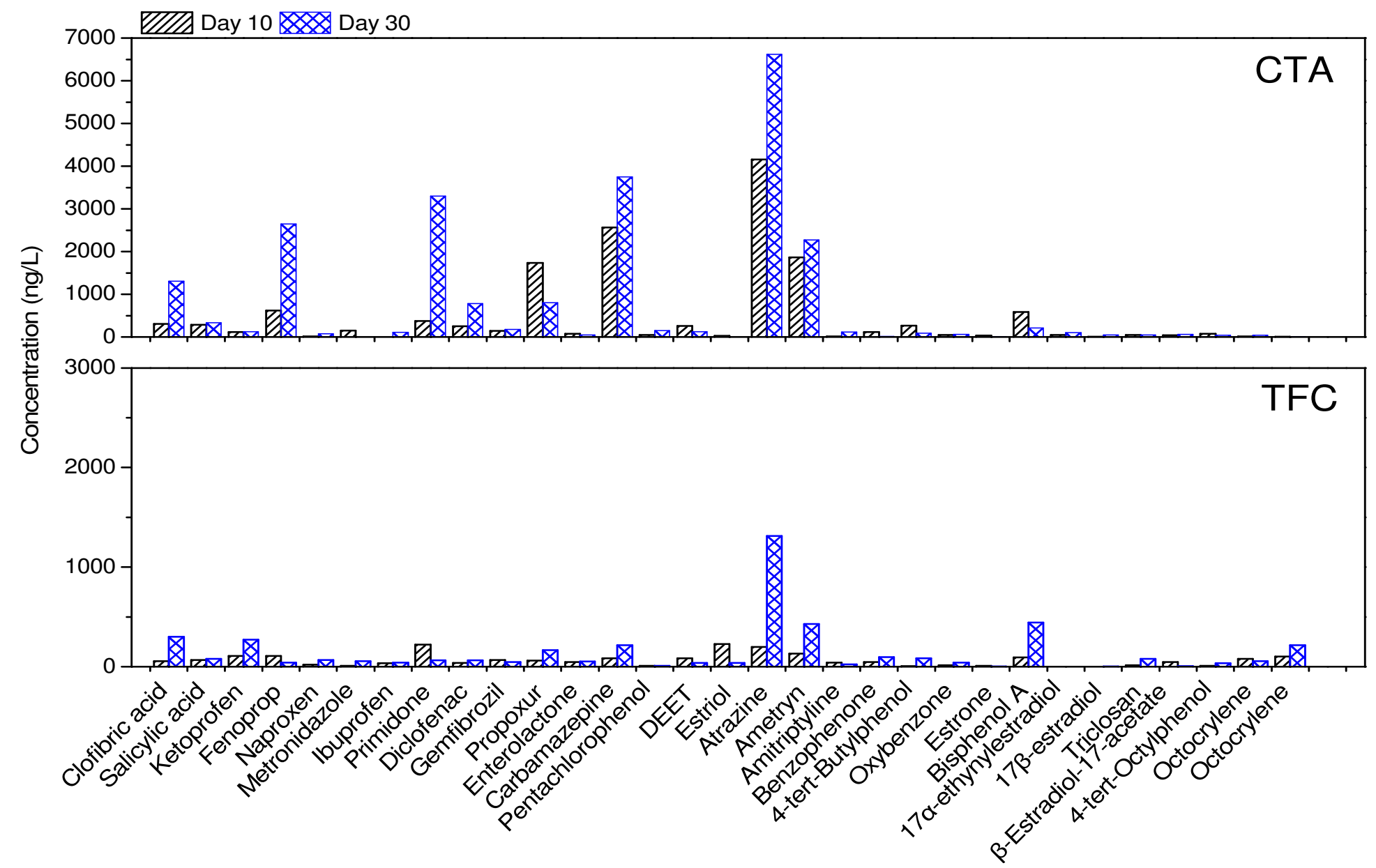

666

667 Figure S4: TrOC concentrations in the draw solution on day 10 and 30 during OMBR-RO operation using the CTA and TFC FO membrane.

668 Experimental conditions are shown in the caption of Figure S2. 
Table S1: Key physicochemical properties of the synthetic wastewater (average \pm

670 standad deviation from 18 measurements during the two OMBR-RO operation)

Parameters

Conductivity $(\mu \mathrm{S} / \mathrm{cm})$

$\mathrm{pH}$

Total Organic Carbon (mg/L)

Total Nitrogen $(\mathrm{mg} / \mathrm{L})$

Ammonium (mg/L)

Phosphate $(\mathrm{mg} / \mathrm{L})$

\section{Synthetic Wastewater}

$321 \pm 15$

$6.2 \pm 0.3$

$141.9 \pm 11.2$

$23.5 \pm 3.2$

$10.6 \pm 1.0$

$11.1 \pm 1.8$

672 Table S2: Physicochemical properties of 30 TrOCs investigated in this study.

\begin{tabular}{|c|c|c|c|c|c|}
\hline Compounds & $\begin{array}{c}\text { Chemical } \\
\text { Formula }\end{array}$ & $\begin{array}{c}\text { Log } \mathrm{D} \\
(\mathrm{pH} 8)\end{array}$ & $\begin{array}{c}\mathrm{MW} \\
(\mathrm{g} / \mathrm{mol})\end{array}$ & $\mathrm{pKa}$ & Chemical Structure \\
\hline Clofibric acid & $\mathrm{C}_{10} \mathrm{H}_{11} \mathrm{ClO}_{3}$ & -1.29 & 214.6 & 3.18 \\
\hline Salicylic acid & $\mathrm{C}_{7} \mathrm{H}_{6} \mathrm{O}_{3}$ & -1.14 & 138.1 & 3.01 \\
\hline Ketoprofen & $\mathrm{C}_{16} \mathrm{H}_{14} \mathrm{O}_{3}$ & -0.55 & 254.3 & 4.23 \\
\hline Fenoprop & $\mathrm{C}_{9} \mathrm{H}_{7} \mathrm{Cl}_{3} \mathrm{O}_{3}$ & -0.28 & 269.5 & 2.93 \\
\hline Naproxen & $\mathrm{C}_{14} \mathrm{H}_{14} \mathrm{O}_{3}$ & -0.18 & 230.3 & 4.84 \\
\hline Metronidazole & $\mathrm{C}_{6} \mathrm{H}_{9} \mathrm{~N}_{3} \mathrm{O}_{3}$ & -0.14 & 171.2 & 14.44 \\
\hline
\end{tabular}




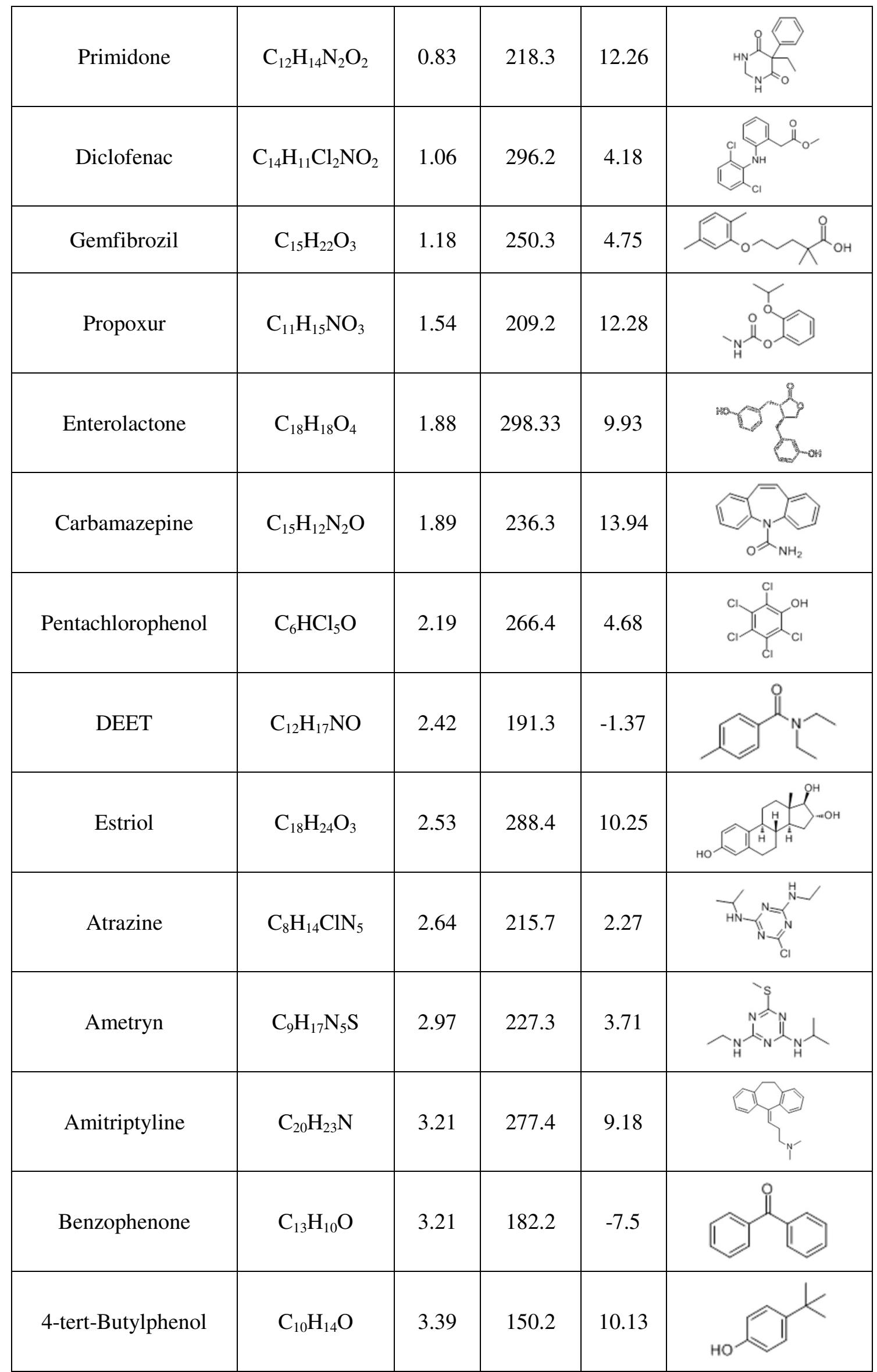




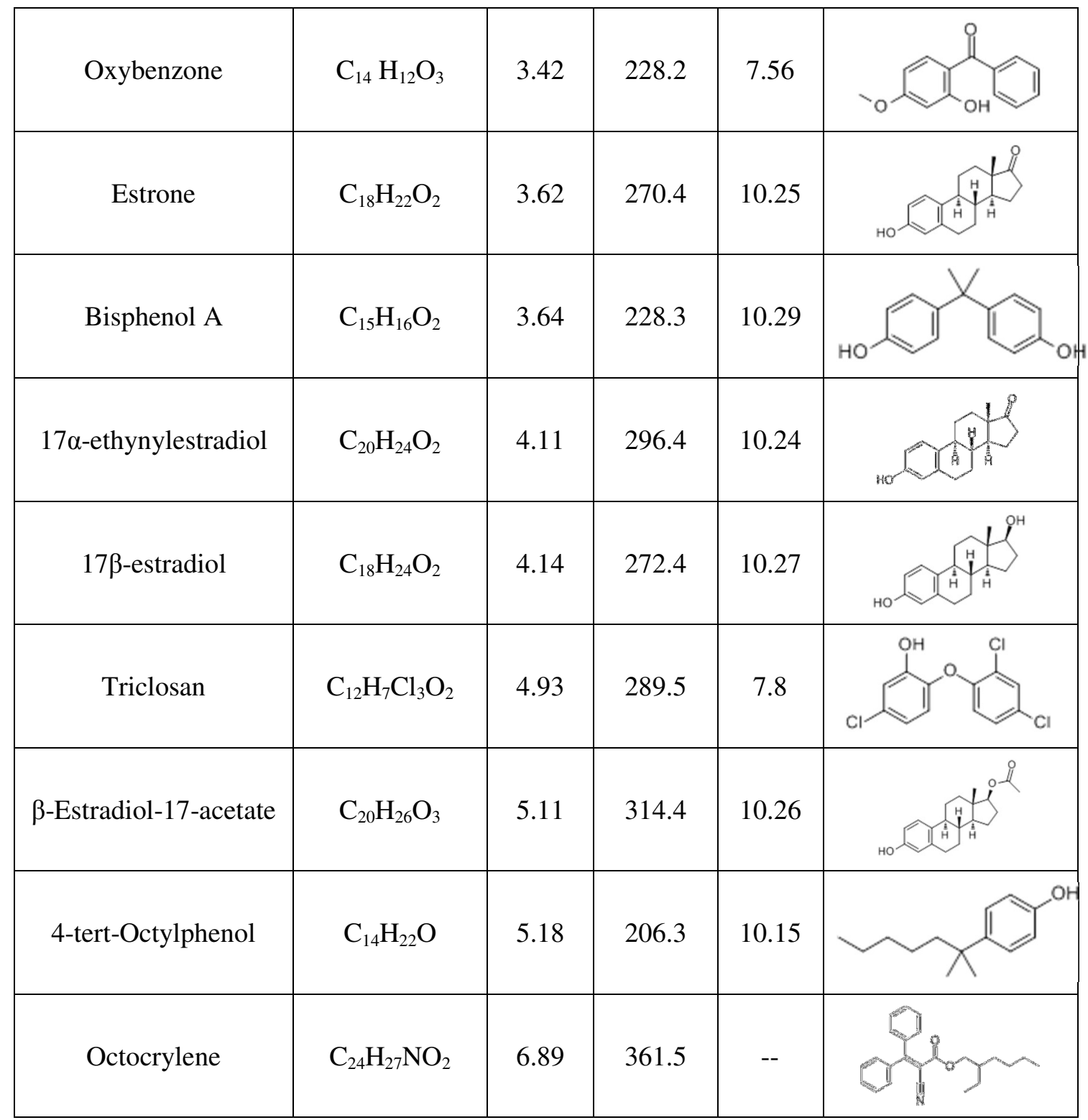

673 Note: Information in this table was obtained from SciFinder Scholar (ACS) database. 
Table S3: Key properties of the FO and RO membranes used in this study (avearge

675 values \pm standard deviation from duplicate measurements).

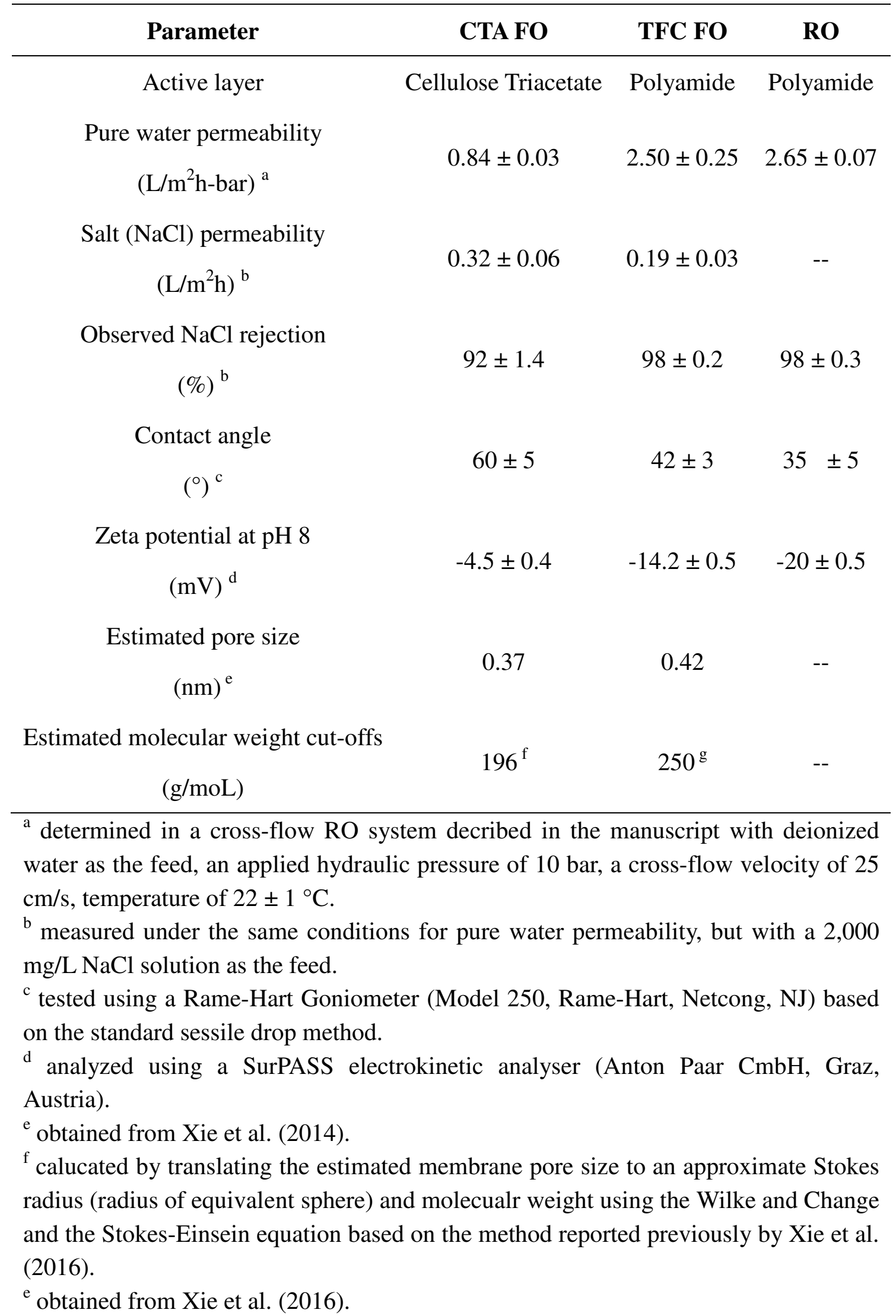




\section{Reference}

692 M. Xie, L.D. Nghiem, W.E. Price, and M. Elimelech, Relating rejection of trace 693 organic contaminants to membrane properties in forward osmosis: Measurements, 694 modelling and implications. Water Res., 2014, 49: 265-274.

695 M. Xie, S.R. Gray, Transport and accumulation of organic matter in forward osmosis $696-$ reverse osmosis hybrid system: Mechanism and implications. Sep. Purif. 697 Technol., 2016, 167: 6-16.

698

699

700

701 